\title{
Frédéric Tinguely, Le voyageur aux mille tours. Les ruses de l'écriture du monde à la Renaissance
}

\section{Michele Mastroianni}

\section{(2) OpenEdition}

1 Journals

\section{Edizione digitale}

URL: http://journals.openedition.org/studifrancesi/411

DOI: 10.4000/studifrancesi.411

ISSN: 2421-5856

\section{Editore}

Rosenberg \& Sellier

\section{Edizione cartacea}

Data di pubblicazione: 1 aprile 2015

Paginazione: 137

ISSN: 0039-2944

\section{Notizia bibliografica digitale}

Michele Mastroianni, «Frédéric Tinguely, Le voyageur aux mille tours. Les ruses de l'écriture du monde à

la Renaissance », Studi Francesi [Online], 175 (LIX | I) | 2015, online dal 01 avril 2015, consultato il 18 septembre 2020. URL : http://journals.openedition.org/studifrancesi/411 ; DOI : https://doi.org/ 10.4000/studifrancesi.411

Questo documento è stato generato automaticamente il 18 settembre 2020.

\section{(c)}

Studi Francesi è distribuita con Licenza Creative Commons Attribuzione - Non commerciale - Non opere derivate 4.0 Internazionale. 


\title{
Frédéric Tinguely, Le voyageur aux mille tours. Les ruses de l'écriture du monde à la Renaissance
}

\author{
Michele Mastroianni
}

\section{NOTIZIA}

FRÉDÉRIC TINGUELY, Le voyageur aux mille tours. Les ruses de l'écriture du monde à la Renaissance, Paris, Champion, 2014 («L'Atelier des voyages», 10), pp. 244.

Dopo gli ultimi anni in cui si sono moltiplicati studi e edizioni di testi di viaggio del Cinquecento - basti pensare ai magistrali interventi di Frank Lestringant su Thevet e Léry - Frédéric Tinguely, grande esperto della letteratura di viaggio del Cinque e Seicento, pubblica un interessante lavoro d'insieme, utile per leggere i testi di questa letteratura non solo come un grande repertorio documentario di valore storico o antropologico, ma anche come un corpus che obbedisce a precise e sottili strategie di scrittura. Il campo studiato va dai racconti dei pellegrinaggi in Terra Santa alle lettere dei gesuiti della Nouvelle France all'Histoire d'un voyage faict en la terre du Bresil di Jean de Léry, con una particolare attenzione anche a un testo della letteratura canonica quale il Journal de Voyage di Montaigne. L'A. apre il suo discorso all'insegna dell'écriture odysséenne (pp. 11-20) a significare la particolare prospettiva degli scrittori rinascimentali di viaggio, in quanto «l'art du voyage odysséen conjugue de façon inespérée la passion pour l'ailleurs et le refus, cher aux humanistes, de la perte d'identité, de la dissolution du sujet dans l'immensité géographique».

2 La prima parte del volume («Infléchir les modèles», pp. 23-78) «s'attache à dégager, dans les relations orientales toujours riches en phénomènes de réécriture, la discrète reconfiguration des modèles génériques et des matériaux textuels empruntés, leur adaptation fine à des nouveaux contextes idéologiques ou épistémologiques». Una seconda parte («Tours oculaires», pp. 81-139) «aborde les stratégies scopiques - mais 
aussi les dispositifs descriptifs qui les prolongent dans un corpus plus diversifié où les vréalités levantines, américaines et romaines posent toujours des problèmes spécifiques à celui qui les observe et entreprend de les donner à voir». Una terza parte («L'aventure de la connaissance: autour de Jean de Léry», pp. 143-180) si occupa dell'opera di Léry, uno dei maggiori esponenti della storia di viaggio esotico, «afin de mettre au jour les ingénieux procédés narratifs qui permettent de dynamiser la description du lointain et d'opérer de la sorte la délicate synthèse de l'aventure et de l'inventaire». Una quarta sezione infine («Devenir autre», pp. 183-220) concentra l'attenzione su Montaigne e sulle relazioni dei missionari gesuiti nel Nuovo Mondo prendendo per oggetto la dimensione propriamente metamorfica dei loro testi. 